\title{
An Analysis of Thorium-Salted Fuels to Improve Uranium Utilization in the Once-Through Fuel Cycle
}

\author{
E. A. Eschbach \\ E. T. Merrill \\ A. W. Prichard
}

September 1981

Prepared for the U.S. Department of Energy under Contract DE-AC06-76RLO 1830

Pacific Northwest Laboratory

Operated for the U.S. Department of Energy by Battelle Memorial Institute 


\title{
NOTICE
}

This report was prepared as an account of work sponsored by the United States Government. Neither the United States nor the Department of Energy, nor any of their employees, nor any of their contractors, subcontractors, or their employees, makes any warranty, express or implied, or assumes any legal liability or responsibility for the accuracy. completeness or usefulness of any information, apparatus, product or process disclosed, or represents that its use would not infringe privately owned rights.

The views. opinions and conclusions contained in this report are those of the contractor and do not necessarily represent those of the United States Government or the United States Department of Energy.

\author{
PACIFIC NORTHWEST LABORATORY \\ operated by \\ BATTELLE \\ for the \\ UNITED STATES DEPARTMENT OF ENERGY \\ Under Contract DE-AC06-76RLO 1830
}

\author{
Printed in the United States of America \\ Available from \\ National Technical Information Service \\ United States Department of Commerce \\ 5285 Port Royal Road
}

Springfield, Virginia 22151

Price: Printed Copy \$.

$\because$ Microfiche $\$ 3.00$

NTIS

-Pages Selling Price

$\begin{array}{ll}001-025 & \$ 4.00 \\ 026-050 & \$ 4.50 \\ 051-075 & \$ 5.25 \\ 076-100 & \$ 6.00 \\ 101-125 & \$ 6.50 \\ 126-150 & \$ 7.25 \\ 151-175 & \$ 8.00 \\ 176-200 & \$ 9.00 \\ 201-225 & \$ 9.25 \\ 226-250 & \$ 9.50 \\ 251-275 & \$ 10.75 \\ 276-300 & \$ 11.00\end{array}$


AN ANALYSIS OF THORIUM-SALTED FUELS

TO IMPROVE URANIUM UTILIZATION IN THE ONCE-THROUGH FUEL CYCLE

E. A. Eschbach

E. T. Merrill

A. W. Prichard

September 1981

Prepared for the U.S. Department of Energy under Contract DE-AC06-76RL0 1830

Pacific Northwest Laboratory Operated for the U.S. Department of Energy by Battelle Memorial Institute 


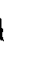




\section{CONCLUSIONS AND STUDY HIGHLIGHTS}

Calculations and analyses indicate that no improvement can be achieved in uranium utilization for the once-through LWR fuel cycle over use of slightly enriched uranium by employing thorium distributed with uranium. The study included thorium additions: 1) in slight amounts (i.e., salting), 2) in larger amounts, in either intimately mixed or in duplex pellets, 3) in spectrally shifted or not spectrally shifted reactors, and 4) in three- or five-year reactivity 1 imited exposures. (Seed blankets were not analyzed.)

Calculations were made by independent investigators at two levels of reactor physics sophistication, simple and essentially rigorous. Both sets of calculations yielded approximately the same results. While use of thoriumuranium combinations improves the initial conversion ratio, requiring slight increases in enrichment of the uranium component, the reactivity lifetime was not extended enough to override the additional uranium required by the thorium additions. In essence, additional fertility afforded by the thorium at the outset of fuel exposure, which increases the conversion ratio, could not be reduced at the end of the exposure so as to increase the reactivity lifetime, even though ${ }^{233} U$ is bred.

These negative results may appear anomalous since ${ }^{233} U$ 's fission-to-capture ratio is higher than ${ }^{239} \mathrm{Pu}$ 's in LWRs. However, extensive diagnostic analys is showed that the effective fission cross-section of the bred ${ }^{233} U$ relative to ${ }^{239} \mathrm{Pu}$ 's in typical LWR neutron spectra is not large enough for ${ }^{233} \mathrm{U}$ to make as great a contribution to end-of-life reactivity as ${ }^{239} \mathrm{Pu}$ in a slightly enriched uranium fuel element. A general relationship was developed showing that ${ }^{233} \mathrm{U}$ 's reactivity contribution relative to ${ }^{239} \mathrm{Pu}$ 's is lower in fuel configurations such as slightly enriched uranium LWR fuel loads since they involve relatively high concentrations of thermal neutron absorbers. On the other hand, ${ }^{233} \mathrm{U}$ 's reactivity contribution appears more positive for reactors that involve lower average concentrations of thermal neutron absorbers (e.g., HWRs and seed-blanket LWRs; these reactors are "gray" rather than "black"). 
of course, were ${ }^{238} U$-thorium fuels reprocessed, the recovered ${ }^{233} U$ would increase the amount of fissile fuel available for recycle, which could, in principle, increase uranium utilization, but may not reduce fuel cycle costs because of reprocessing and fabrication complications associated with recovery and re-using of ${ }^{233} U$ intimately mixed with ${ }^{238} U$.

It was also observed that the thorium-salted fuels exhibit substantially flatter reactivity characteristics with exposure time. This could lead to reductions in the degree to which fuels need be shuffled during long exposure periods ( 3 to 5 years). Spectral shift helped the utilization of uranium and thorium; moreover, in reactors such as the BWR, where large differences in moderating power may exist, it is suspected that judicious use of thorium in local areas may be attractive. (a)

The findings of this study coupled with other ${ }^{233} \mathrm{U}$-plutonium comparative analyses completed in the early 1960s and reviewed in the late 1970s help explain why use of ${ }^{233} U$-thorium has not been a compelling fueling alternative to LWRs fueled with slightly enriched uranium. In short, the nuclear power industry appears properly launched with uranium fuels, whether spent fuel is reprocessed or not.

(a) R. L. Crowther. 1979. "Once-Through and Longer Term Use of Thorium in Light Water Reactors." R. S. Greeley, ed., the MITRE Corporation, McLean, Virginia, p. 277. 
CONTENTS

CONCLUSIONS AND STUDY HIGHLIGHTS $\quad$ •

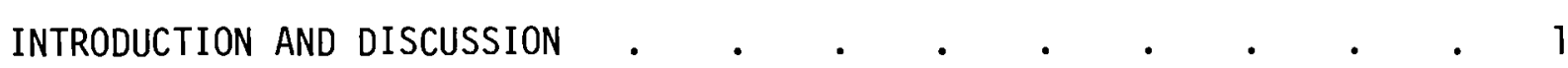

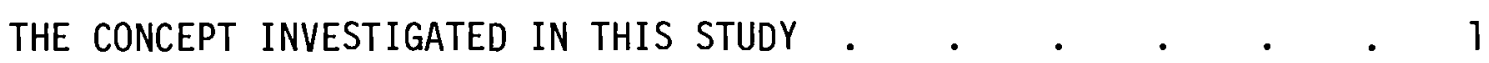

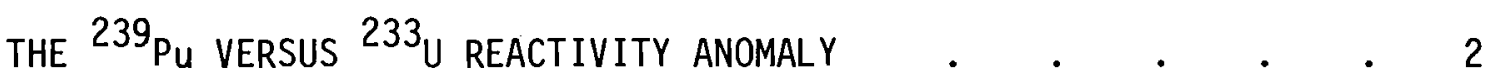

THE EMBODIMENTS AND STRATEgIES EXAMINED • • . . . . . 3

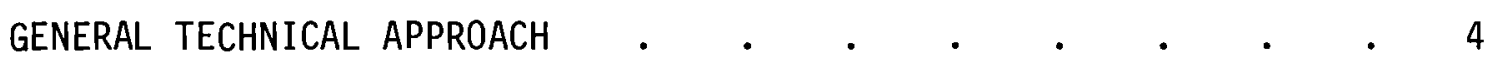

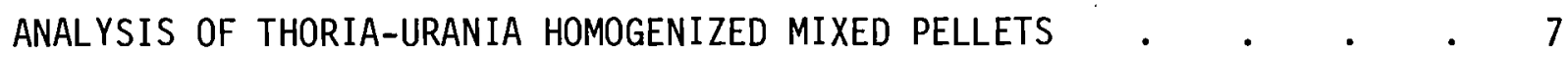

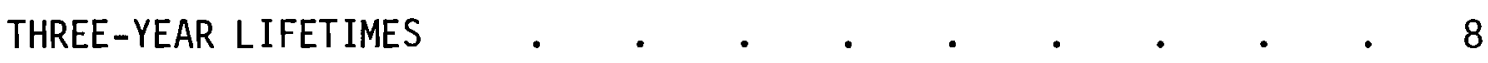

FIVE-YEAR LIFETIMES •

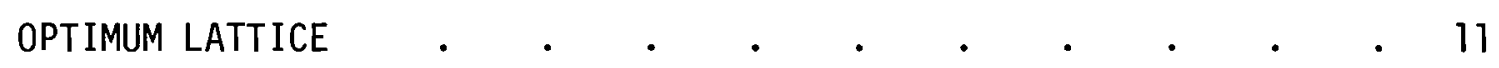

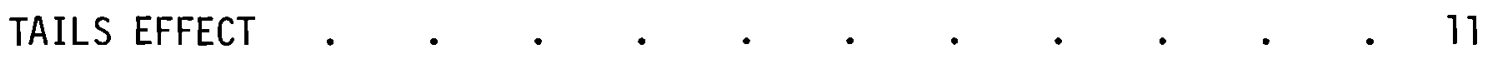

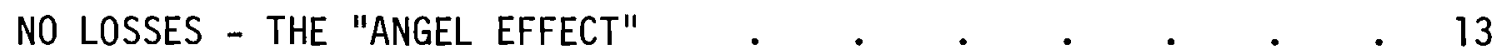

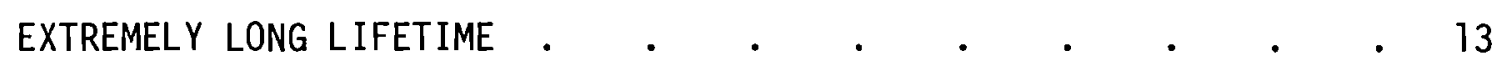

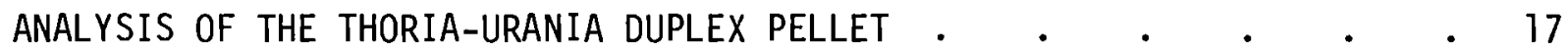

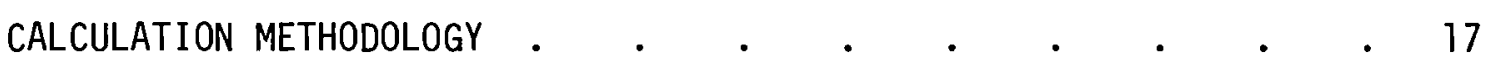

PELLET DESCRIPTION

RESULTS FOR THE THORIA-URANIA DUPLEX PELLET • • • • • • • 18 WHY THORIUM/ ${ }^{233}$ U DOES NOT CONSERVE URANIUM IN ONCE-THROUGH LWRS • • 23

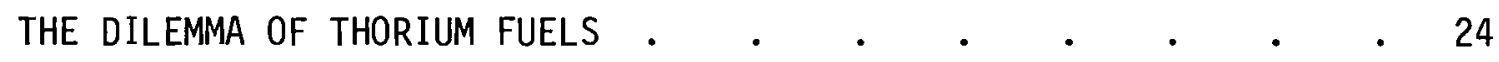

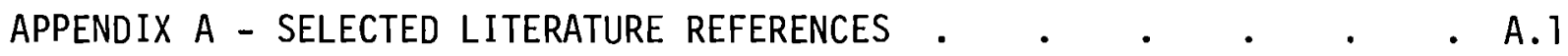
APPENDIX B - CODE COMPARISON 


\section{FIGURES}

1 Calculated Uranium Consumption for 3-Year Reactivity Limited Lifetime, Comparing Fixed and Discrete Spectral Shift Lattices . . 9

2 Calculated Uranium Consumption for 5-Year Reactivity Limited Lifetime, Comparing Fixed and Discrete Spectral Shift Lattices . 10

3 Calculated Uranium Consumption for 5-Year Reactivity Limited Life-

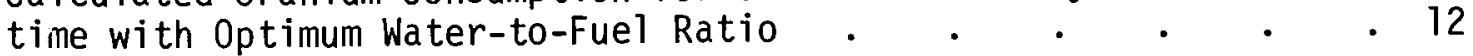

4A Calculated Uranium Consumption for 5-Year Reactivity Limited Lifetime, Comparing 0\% and 0.2\% Tails for Discrete Spectral Shift . 14

4B Calculated Uranium Consumption for 5-Year Reactivity Limited Lifetime, Comparing $0 \%$ and $0.2 \%$ Tails for Fixed Lattices . $\quad$ • 15

5 Calculated Uranium Consumption for 5-Year Reactivity Limited Lifetime, Comparing 0\% and 0.2\% Tails with No Neutron Loss for Control 16

6 Calculated Uranium Consumption for 3-Year Reactivity Limited Lifetime, Comparing 0\% and 0.2\% Tails for the Duplex Pellet . . 19

7 Calculated Uranium Consumption for 5-Year Reactivity Limited Lifetime, Comparing $0 \%$ and $0.2 \%$ Tails for the Duplex Pellet . . 20

8 Influence on Reactivity of Incremental ${ }^{239} \mathrm{Pu}$ and ${ }^{233} \mathrm{U}$ Additions . 25

\section{$\underline{\text { TABLES }}$}

1 Fuel Pin Parameters for the Urania-Thoria Duplex Pellet Comparison 18

B.1 Comparison of Calculated Reactivity Parameters from Several Codes. B.2

B.2 Comparison of Calculated Reactivity Parameters from WIMS and HAMMER

B. 3 Comparison of Calculated $k_{\infty}$ with Burnup for $4.5 \%{ }^{235} \mathrm{U}$ All-Uranium Homogeneous Pellet. 


\section{INTRODUCTION AND DISCUSSION}

The objective of this study is to explore methods of improving the utilization of uranium in the once-through LWR fuel cycle (no spent fuel reprocessing) by judicious introduction of thoria in place of urania. This is to be done in existing LWRs in a manner consistent with present fuel outages and shuffling practices with essentially the same fuel bundle configurations. (a) Currently, the potential for improvement exists by this approach, since neutrons excess to keeping the reactor critical can be absorbed in the ${ }^{238} \mathrm{U}$ to form ${ }^{239} \mathrm{Pu}$, which is available for in-situ fission, to generate heat, and to extend the reactivity lifetime of light water reactor fuel as the ${ }^{235} U$ burns out. In practice, this is significantly imperfect, because of the heterogeneity of the fuel element load in LWRs and the immobility of the fuel except during reactor fuel outages. Accordingly, some of the extra neutrons must be absorbed in control systems, especially excess neutrons from fresh fuel bundles, even though these fresh fuel bundles are placed next to nearly spent fuel bundles.

While provision can be made to enhance the neutron absorption in ${ }^{238} U$, thereby generating additional fissile fuel and reducing neutron losses to control, the extra bred fuel cannot be fully utilized without reprocessing. This "unavailability" occurs because the propensity for absorption of neutrons in the ${ }^{238} \mathrm{U}$ remains throughout the fuel life. This leads to "over-fertility" for the nearly spent fuel, which further reduces the achievable reactivity lifetime above and beyond reactivity reduction associated with neutron absorption in fission products. The use of spectral shift would substantially reduce the effect of overfertility towards the end of 1 ife, but would require design of new LWRs and substantial retrofitting of existing LWRs. Neither fuel reprocessing nor continuous spectral shift capability meet the ground rules set for the objectives of this study.

THE CONCEPT INVESTIGATED IN THIS STUDY

The proposed thermal neutron reactor fuel concept studied herein involves the addition of a judicious amount of thorium to a uranium fuel element so as

(a) Specific embodiments utilizing the epi-thermal fluxes available in the highly voided portion of BWRs were not explored here. 
to increase the fertility of the fuel at the outset of irradiation, thereby absorbing what would otherwise be excess neutrons absorbed in control systems. As exposure continues, the fertility is (hopefully) sufficiently reduced as thorium is depleted by conversion into ${ }^{233} U$, so that nuclear reactivity is prolonged. Basically, uranium is to be conserved through the reduction of neutron absorptions in control systems by the breeding of additional quantities of fissile material, ${ }^{233} U$, which is then available for in-situ fission. In addition, $233 \mathrm{U}$, which has an intrinsically higher neutron yield in thermal neutron reactors than does ${ }^{239} \mathrm{Pu}$, may result in higher reactivity in some fuel configurations, if its effective fission cross-section is large enough. This is a crucial point investigated in this study and outlined below.

\section{THE ${ }^{239}$ PU VERSUS ${ }^{233}$ U REACTIVITY ANOMALY}

There is a school of thought that by virtue of the relative values of eta, ${ }^{233} \mathrm{U}$ should be a superior thermal reactor fuel to ${ }^{239} \mathrm{Pu}$. (Eta, $n$, is the neutrons yielded per neutron absorbed.) It can be computed for fissile species per se, i.e., "isolated" or it can be computed for an aggregate of fuel components such as for natural uranium. (For isolated ${ }^{233} \mathrm{U}$, eta is about 2.3, ${ }^{235} \mathrm{U}$ about 2 , and ${ }^{239} \mathrm{Pu}$ about 1.9-1.95 in thermal neutron spectrums.) The "eta" of natural uranium is about 1.35 in most thermal neutron reactors.

However, in typical LWR neutron spectra, ${ }^{239} \mathrm{Pu}^{\prime} \mathrm{s}$ neutron fission crosssection is greater than $233^{\prime}{ }^{\prime} s$ and this is an important contribution to maintaining nuclear reactivity when other significant neutron absorbers are present. Thus, from the standpoint of maintaining reactivity, atom for atom, ${ }^{239} \mathrm{Pu}$ may be more effective than ${ }^{233} \mathrm{U}$ when there is competition for thermal neutrons, mainly from fission products and from the effective thermal crosssections of ${ }^{238} \mathrm{U}$ and ${ }^{232} \mathrm{Th}$. In the epi-thermal region (0.6-5000 ev) ${ }^{233} \mathrm{U}$ has a higher fission cross-section than does ${ }^{239} \mathrm{Pu}$ or ${ }^{235} \mathrm{U}$. This effect may be beneficially exploited in BWRs, as described by Crowther in recent studies. (a)

(a) H. E. Williamson, et al. 1978. Assessment of Utilization of Thorium in BWRs. NEDG 24073. General Electric Co. San Jose, California.

M. J. Colby, D. B. Townsen and C. L. Kunz. Safety Analys is of ThoriumBased Fuels in the G. E. Standard BWR. NEDG 24817. General Electric Co. San Jose, California. 
The effect of a high ${ }^{239} \mathrm{Pu}$ cross-section on reactivity is particularly evident in slightly enriched uranium fuel. This fuel starts out burnup with ${ }^{235} \mathrm{U}$ as the fissile component, and converts at only about 60 percent efficiency to plutonium as the ${ }^{235} \mathrm{U}$ burns out, but the nuclear reactivity of the fuel load remains remarkably constant for some time. That is, the reactivity drop does not correspond with the relative drop in fissile concentration because the absorption cross-section of ${ }^{239} \mathrm{Pu}$ is almost twice that of ${ }^{235} \mathrm{U}$. Unfortunately, ${ }^{233}$ U's thermal fissile cross-section is about the same as that of ${ }^{235} \mathrm{U}$. Therefore, while substituting ${ }^{233} U$ for ${ }^{235} U$ should show a reactivity gain, because eta for ${ }^{233} \mathrm{U}$ is larger, substituting ${ }^{233} \mathrm{U}$ (or substituting ${ }^{235} \mathrm{U}$ ) for plutonium may show a loss of reactivity. This point is demonstrated quantitatively in this report.

\section{THE EMBODIMENTS AND STRATEGIES EXAMINED}

Thus, there are two facets of the proposed thorium salting in uranium fuel. First, and most important, is that of a burnable "fertile poison" achieved through the use of just enough thorium so, at the outset of fuel exposure, the fertility of the fuel will be greater (i.e., resonsance escape probability will be reduced) and as exposure proceeds, the fertility drops as the thorium burns out. And second is the extent that the improved neutron reproduction of ${ }^{233} \mathrm{U}$ can override the ${ }^{233} \mathrm{U}$ 's lower fissile cross-section as compared with that of ${ }^{239} \mathrm{Pu}$. Without calculation, it is not obvious that a successful embodiment can be realized. Moreover, for longer fuel exposures, the burnout effects of thoria should be enhanced (but the $10{ }^{233} \mathrm{U}$ absorption cross-section problem will not). In this study fuel exposures of 3 and 5 years were routinely calculated and even long exposure cases were computed to obtain a point of diminishing return ( 7 to 9 years).

The most straightforward embodiment of the burnable poison effect is to mix uniformly a small amount of thorium in uranium. However, by placing the thorium on the outer periphery of a uranium pellet (so-called "duplex pellet") rather than mixing, the burnable poison aspects should be increased, particularly from the standpoint of enhancing thermal neutron absorption in the 
thorium at the outset of irradiation, and hopefully then preferentially fissioning the bred ${ }^{233} U$ as compared with underlying plutonium and ${ }^{238} U$ (the "onion skin" effect). Both uniform mixing and the duplex pellets were studied in this program.

The burnable poison effect may also be increased by spectral shift adjustment, to decrease resonance absorption as burnup proceeds, but not necessarily requiring a continuous adjustability of a spectral shift reactor (e.g., as initially described by Edlund, (a) which involved the dilution of $\mathrm{D}_{2} \mathrm{O}$ with 1 ight water). Rather, components could be adjusted as discrete entities during reactor shutdowns so that the effective moderator-to-fuel ratio can be increased by removal of dummy rods, by rebundling the fuel rods at increased spacings, by introducing water into initially empty tubes within the fuel bundle, or by placing fuel bundles in and out of the boiling region in a BWR. The spectral shift steps towards increased moderation would reduce the absorption of resonance neutrons in whatever thorium nuclei that are left, and more particularly, would reduce resonance absorption in the ${ }^{238} \mathrm{U}$, which will not have appreciably diminished in concentration. Thus, discrete spectral shift is recognized as a possible practical embodiment, and idealized spectral shift is evaluated in this study to see how effective the discrete spectral shift may be. Spectral shift is also evaluated in slightly enriched uranium cycles for comparison.

GENERAL TECHNICAL APPROACH

Calculations of the various embodiments were conducted at two levels of sophistication. First, for guiding purposes and to provide within an economic computing time an essentially complete holistic view, a rapid survey code was used. This code is coupled with a uranium balance calculation, and is useful to indicate areas of promise. Second, a more rigorous and time-consuming code was used selectively for more detailed examinations. The simplified code has

(a) M. C. Edlund and G. K. Rhode. 1957. Thorium and Uranium Fuel Cycles for Spectra Shift Controlled Pressurized Water Reactors. ANS Third Annual Meeting, June 1977, Paper 4-1. 
many 1 imitations, particularly with respect to the duplex pellet configurations, wherein thorium was placed on the outside of the pellet, and thereby one has changes in effective cross-sections occurring rapidly as one passes from the thorium to the uranium region within the fuel pellet. The rapid fuel analys is was done using the ALTHAEA code. The duplex pellets and rigorous calculations were performed with the WIMS code, named for the Winfrith Improved Multigroup Scheme, a British neutronics computer code that has been used by others to analyze duplex pellet systems having onion skin effect as well as uranium/thorium systems in general. In addition, corroborating diagnostics were made using versions of LEOPARD, HAMMER, and EGGNIT.

Natural uranium utilization calculations included all of the natural uranium necessary from mines, including losses through equilibrium fueling campaigns, and are quoted in tons of natural uranium in $\mathrm{U}_{3} \mathrm{O}_{8}$ per year per 1000 MWe year or giga-watt year-electric $=$ GWYre $(33$ percent therma 1 to electrical efficiency at 80 percent plant factor). 


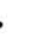

.

. 


\section{ANALYSIS OF THORIA-URANIA HOMOGENIZED MIXED PELLETS}

The rapid survey code $\operatorname{ALTHAEA}^{(a)}$ was used in its zero-dimensional reactor mode to calculate the annual natural uranium consumption for various homogeneous mixtures of urania and thoria. This code handles the fuel bundle spatially in the sense of accepting the unit cell dimensions, temperatures, material descriptions, and desired power level as input and calculates the changing compositions and k-infinity $\left(k_{\infty}\right)$ as a function of time (and burnup). The code iterates as compositions change and recalculates from the spatial characteristics the appropriate flux depressions, etc. The code has several options for estimating the useful lifetime of an equilibrium fuel batch. Except for one final series of calculations discussed below, standard fuel shuffling during outages was simulated, with the end of reactivity. life presumed when the flux-time $(b)$ averaged $k_{\infty}$ fell to 1.05 . This is equivalent to an allowance of 5 percent for neutron leakage and absorptions in control materials. The reactor description was based on the Combustion Engineering System 80 design. Simplified calculations were made for the following cases:

- Uniform mixtures 0-99 percent thorium

- Three-year lifetimes with and without spectral shift

- Five-year lifetimes with and without spectral shift

- Optimum lattice

- Enrichment tails effect

- No losses ("angel effect")

- Extremely long lifetimes.

As discussed, it was hoped that from 1 to 10 percent thoria would be beneficial by lowering reactivity early in the life through absorption of excess neutrons into thorium, and then the thorium would burn out, leaving fissile ${ }^{233} \mathrm{U}$ to extend reactivity late in 1 ife, as well as gain reactivity through the reduced fertility associated with the thorium burnout. For this reason, urania

(a) E. T. Merri11. 1971. ALTHAEA: A One-Dimensional, Two-Group Diffusion Code with an Effective Four-Group Burnup. BNWL-462, Pacific Northwest Laboratory, Richland, Washington.

(b) Flux-time average as used herein is the time weighted average of flux multiplied by time interval weighted $k_{\infty}$. 
fuels with 1, 3, 10, and 30 percent thoria were examined. It was also useful to calculate 100 percent urania for comparison. Cases with mostly thoria containing urania to provide ${ }^{238} U$ at $30,10,3,1$, and 0.26 percent in total heavy metal were also included for completeness. In all cases the uranium enrichment was adjusted by iteration to obtain respective lifetimes of 3 and 5 years. It should be noted that as the proportions of thoria are increased, the fuel density decreases; and therefore, for a given delivered energy per cubic centimeter of fuel, the exposure expressed in MWD/T increases.

\section{THREE-YEAR LIFETIMES}

The calculations of the uranium utilization with various amounts of thoria additions for the 3-year lifetimes (about 30,000 MWD/T in uranium) are summarized in Figure 1. Note that the fuel without thoria (at the reader's left) has the lowest natural uranium consumption (180 tons/year) and that the consumption increases rapidly as small amounts of thoria are added. The natural uranium consumption is calculated to be a maximum (245 tons) when about 85 percent of the fuel is thoria and decreases to 220 tons content at essentially pure thoria. The second curve labeled "Discrete Spectral Shift" represents the improvement in uranium consumption that would be available if after about 3 years the fuel is disassembled and reassembled (reconstituted) with about twice the normal water-to-fuel ratio and reinserted in the reactor for additional exposure. Such a reconstitution may not be practical, but it was explored since it was hoped that the softer neutron spectrum would preferentially improve the behavior of the fuels containing thoria. While the calculations indicate that the improvement is greater for the fuels containing thoria, all-urania fuel is still the best (163 tons).

\section{FIVE-YEAR LIFETIMES}

The calculations of uranium utilization for the 5-year lifetimes (about $55,000 \mathrm{MWD} / \mathrm{T}$ in urania) are summarized in Figure 2. Again, the lowest uranium consumption is still achieved by the urania fuel without thorium (reader's 


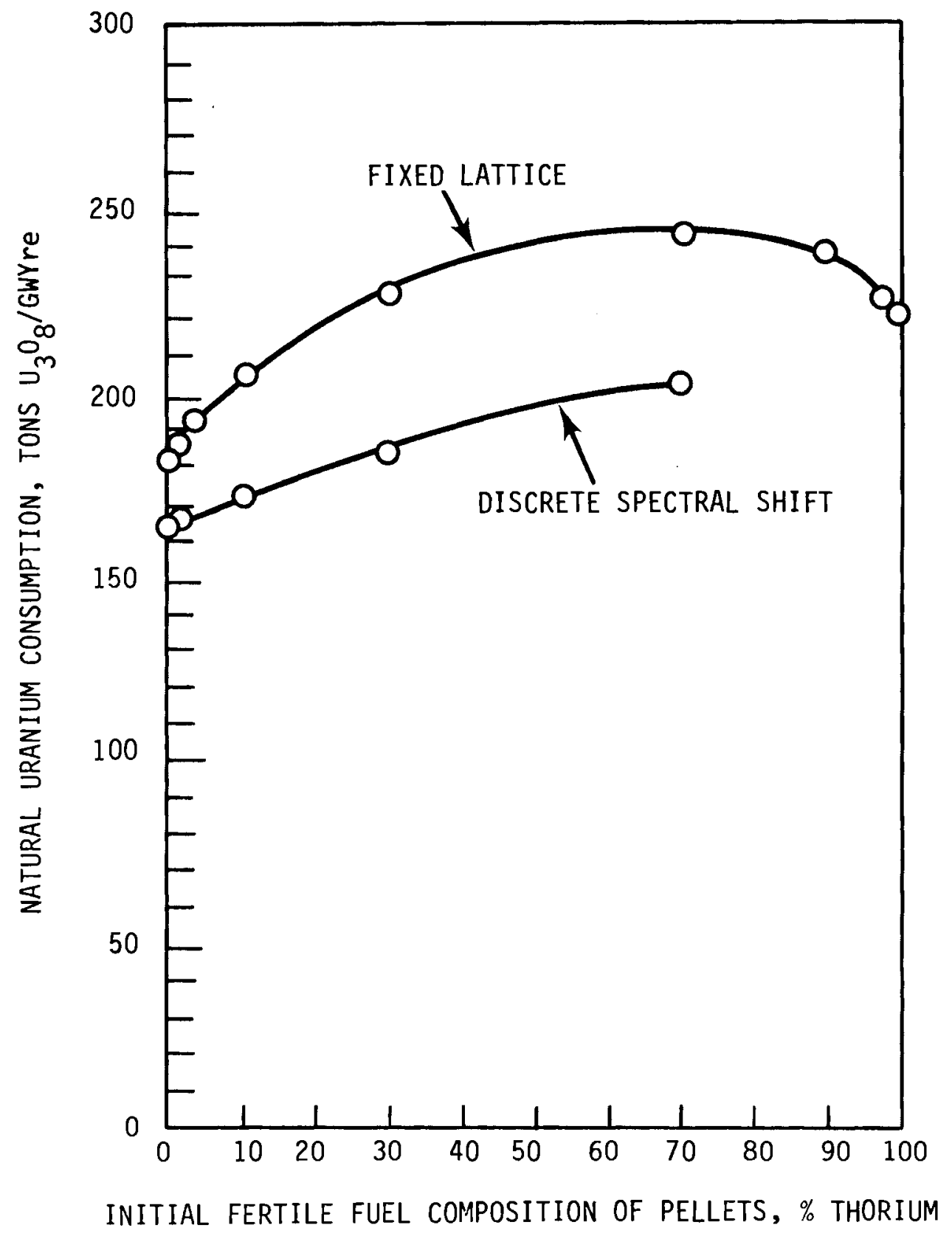

FIGURE 1. Calculated Uranium Consumption for 3-Year Reactivity Limited Lifetime, Comparing Fixed and Discrete Spectral Shift Lattices 


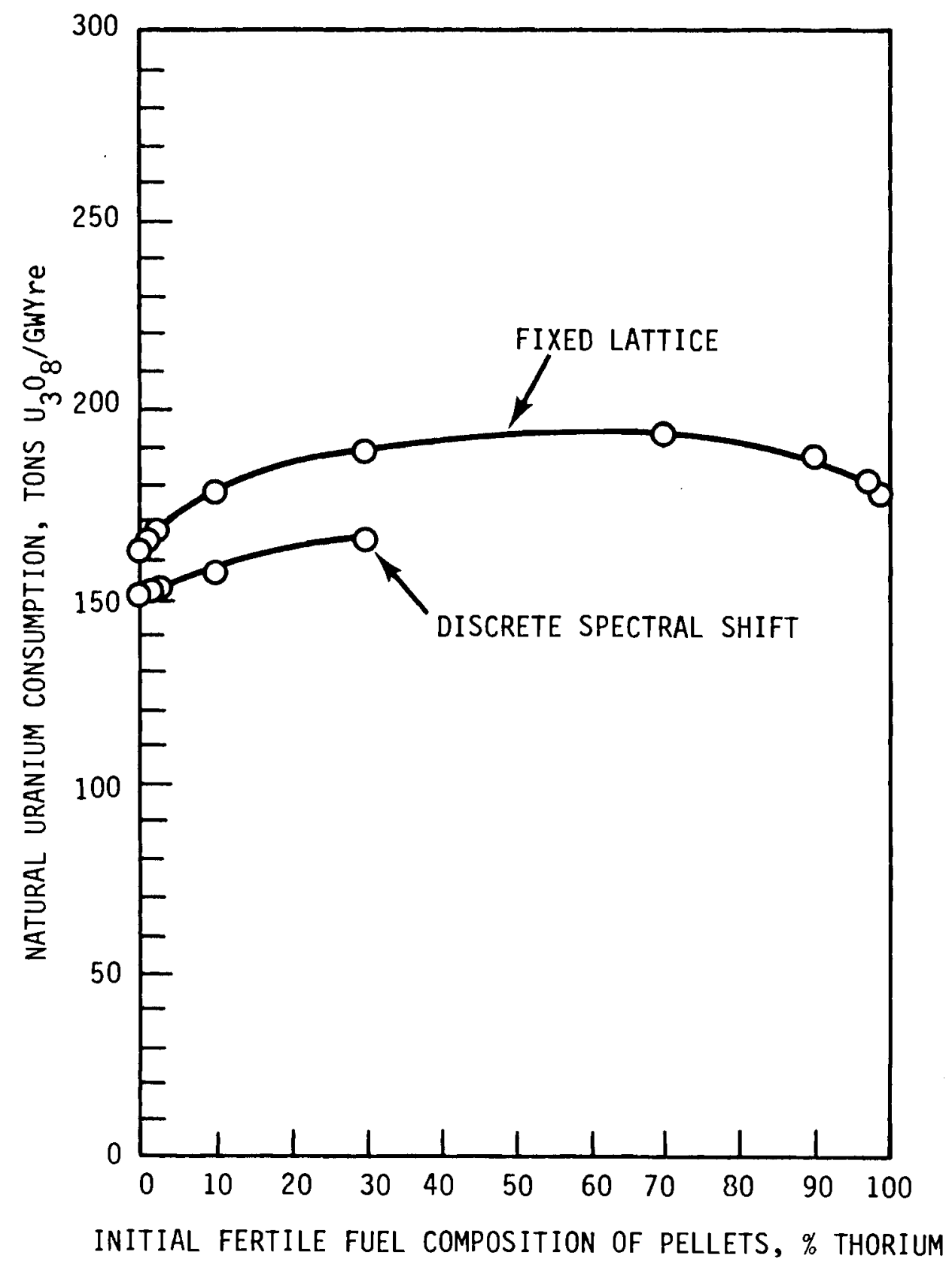

FIGURE 2. Calculated Uranium Consumption for 5-Year Reactivity Limited Lifetime, Comparing Fixed and Discrete Spectral Shift Lattices 
left), even though, as compared with the 3-year curves, uranium consumption is reduced more in the fuels containing thoria than in the urania-only fuel. The curve labeled "Discrete Spectral Shift" represents the uranium consumption that would result if after 5 years in the reactor the fuel could be disassembled and reassembled with about twice the normal water-to-fuel ratio and reinserted in the reactor for an additional period of time. As was the case for the 3-year 1 ifetime, the improvement is greater for the fuels containing thoria than for the all-urania fuels, but the improvement for the urania fuel is still sufficient so that uranium-only fuel remains the lowest consumer of natural uranium. While not studied here, it would appear that in BWRs, (a) judicious use of thorium could be useful in view of the variation of effective moderating power over a boiling water core.

\section{OPTIMUM LATTICE}

Figure 3 presents the uranium consumption that would result if the waterto-fuel ratio yielding the lowest consumption is selected for each fuel composition. It can be noted on the curve labeled "Optimum Lattice" that the optimum water-to-fuel ratio was 2.76 for the a11-urania fuel and increased as the percentage of thoria increased up to 3.16 at 30 percent thoria. The optimum water-to-fuel ratio for 30 percent ${ }^{238} U$ was also 3.16 but decreased as fuels with 1 ess ${ }^{238} \mathrm{U}$ were examined. For the fuel with only .26 percent ${ }^{238} U$, the standard lattice with a water-to-fuel ratio of 2.036 appeared to be optimum. It should be noted that the urania-only fuel continues to have the lowest uranium consumption.

\section{TAILS EFFECT}

At the higher enrichments of uranium required in the fuels containing thoria, more of the uranium consumed will be found in the tails, i.e.,

(a) R. L. Crowther. 1979. "Once-Through and Longer Term Use of Thorium in Light Water Reactors." R. S. Greeley, ed., the MITRE Corporation, McLean, Virginia, pp. 270-293. 


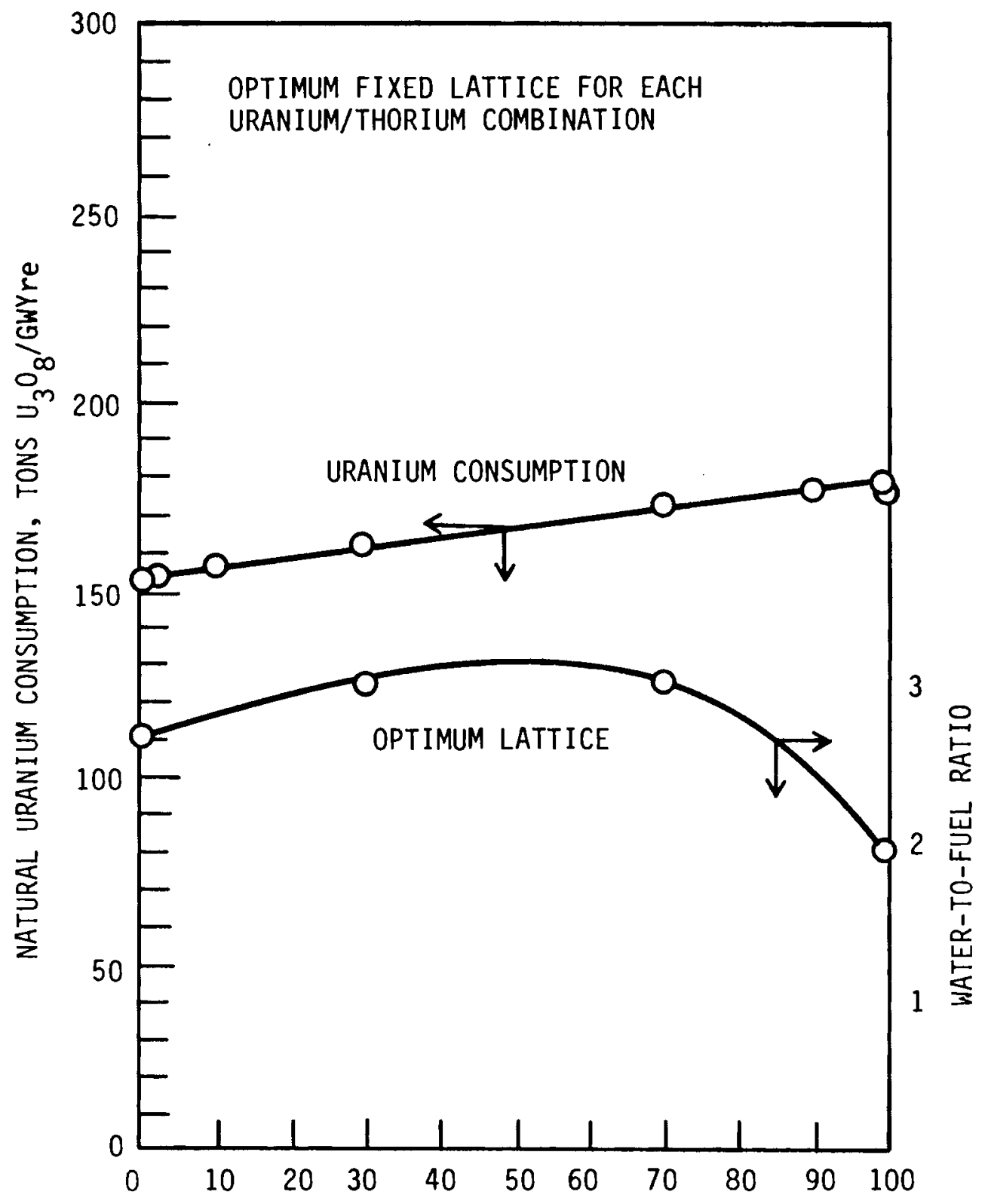

INITIAL FERTILE FUEL COMPOSITION OF PELLETS, \% THORIUM

FIGURE 3. Calculated Uranium Consumption for 5-Year Reactivity Limited Lifetime with Optimum Water-to-Fuel Ratio 
enrichment cascade waste. Therefore, reducing the tails composition $\left({ }^{235} \mathrm{U}\right.$ content) will improve uranium utilization for fuels containing thoria more than it will the urania-only fuel. To illustrate the limit of this effect, zero enrichment tails curves were prepared from the previous 5-year lifetime calculations (Figures 2 and 3 ) and are shown in Figures $4 A$ and $4 B$, respectively. Note that the all-urania fuel still has the lowest uranium consumption for both the reconstituted and standard fuel. Moreover, note throughout all of the figures that reducing the tails composition is a promising method of saving uranium, which requires no changes in reactor fuel core configurations, etc. Thus, it appears that of the methods studied, the largest savings in uranium for once-through fuel cycles would be achieved by lowering enrichment tails.

NO LOSSES - THE "ANGEL EFFECT"

Since the ${ }^{232} \mathrm{Th}^{2}{ }^{233} \mathrm{U}$ system has a higher conversion ratio than the ${ }^{238} \mathrm{U}$ ${ }^{239} \mathrm{Pu}$ system and in-situ burning is enhanced when losses are low (the increased cross-sections of ${ }^{239} \mathrm{Pu}$ will be less important in this instance), a series of calculations was done to define the limit of this effect. They represent perfect, continuous refueling of a very large reactor (no leakage or control absorption which would be achieved were "angels" to move fuel pins throughout exposure, i.e., a truly infinite system). The curve on Figure 5 labeled "Zero Tails" represents the combination of these two extreme conditions and, even then, the all-urania fuel has the lowest uranium consumption. With a $0.2{ }^{235} \mathrm{U}$ tails composition rather than zero, the no-loss curve has an annual uranium consumption of 125 tons/year.

\section{EXTREMELY LONG LIFETIME}

It is difficult to see how any practical once-through cycle can do any better than the "Angel Effect." To check this, calculations of "Angel Effect" fuel exposures longer than 5 years were made. These indicate that uranium consumption is scarcely lessened and starts up at exposure figures of 7 years. Thus, it would appear that for the once-through fuel cycle, if the industry goes to the 5-year system with shuffling at each fuel shutdown, annual uranium consumption will be about 165 tons/year and that the best that a theoretical system can do will be 125. 


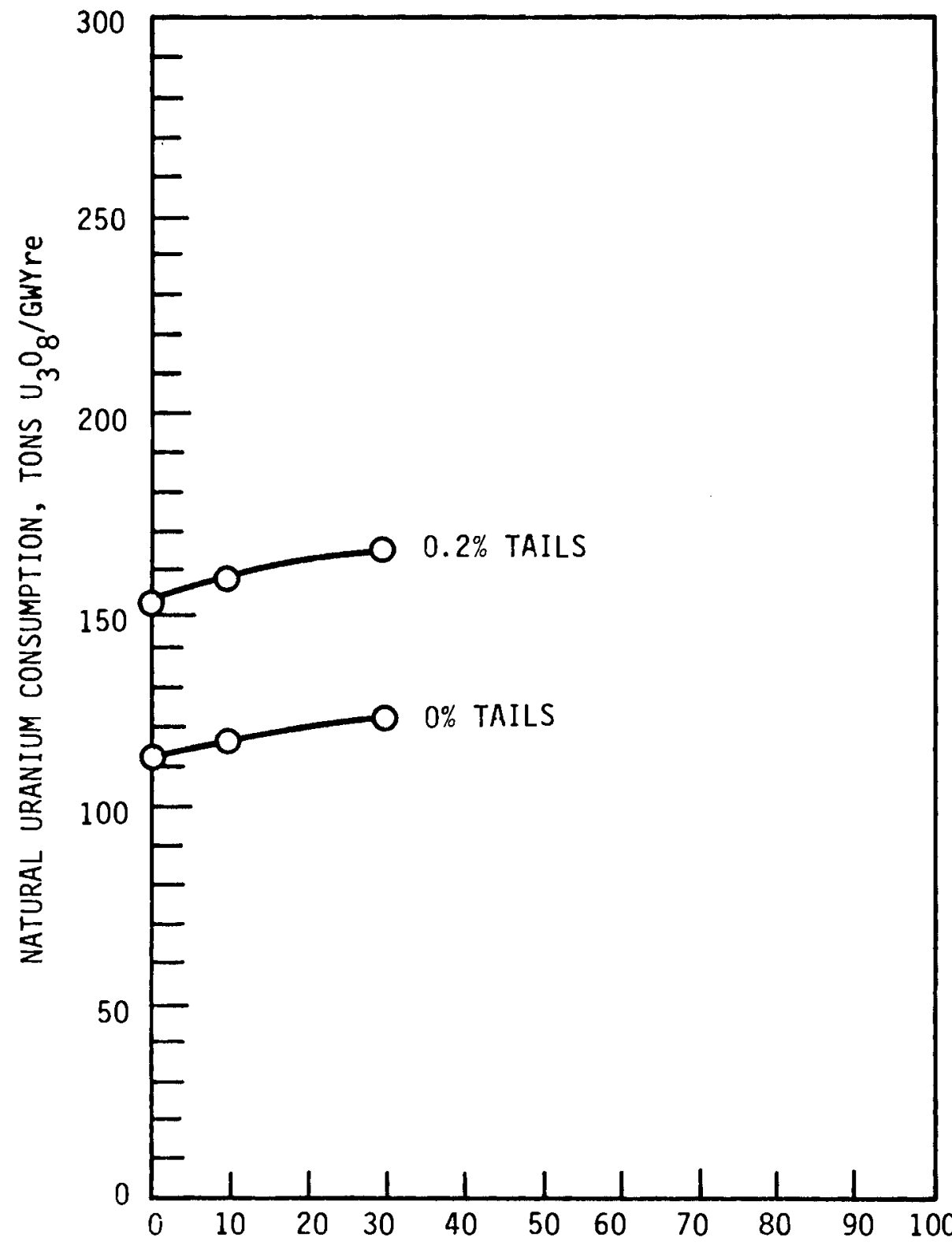

INITIAL FERTILE FUEL COMPOSITION OF PELLETS, \% THORIUM

FIGURE 4A. Calculated Uranium Consumption for 5-Year Reactivity Limited LifeTime, Comparing 0\% and 0.2\% Tails for Discrete Spectral Shift 


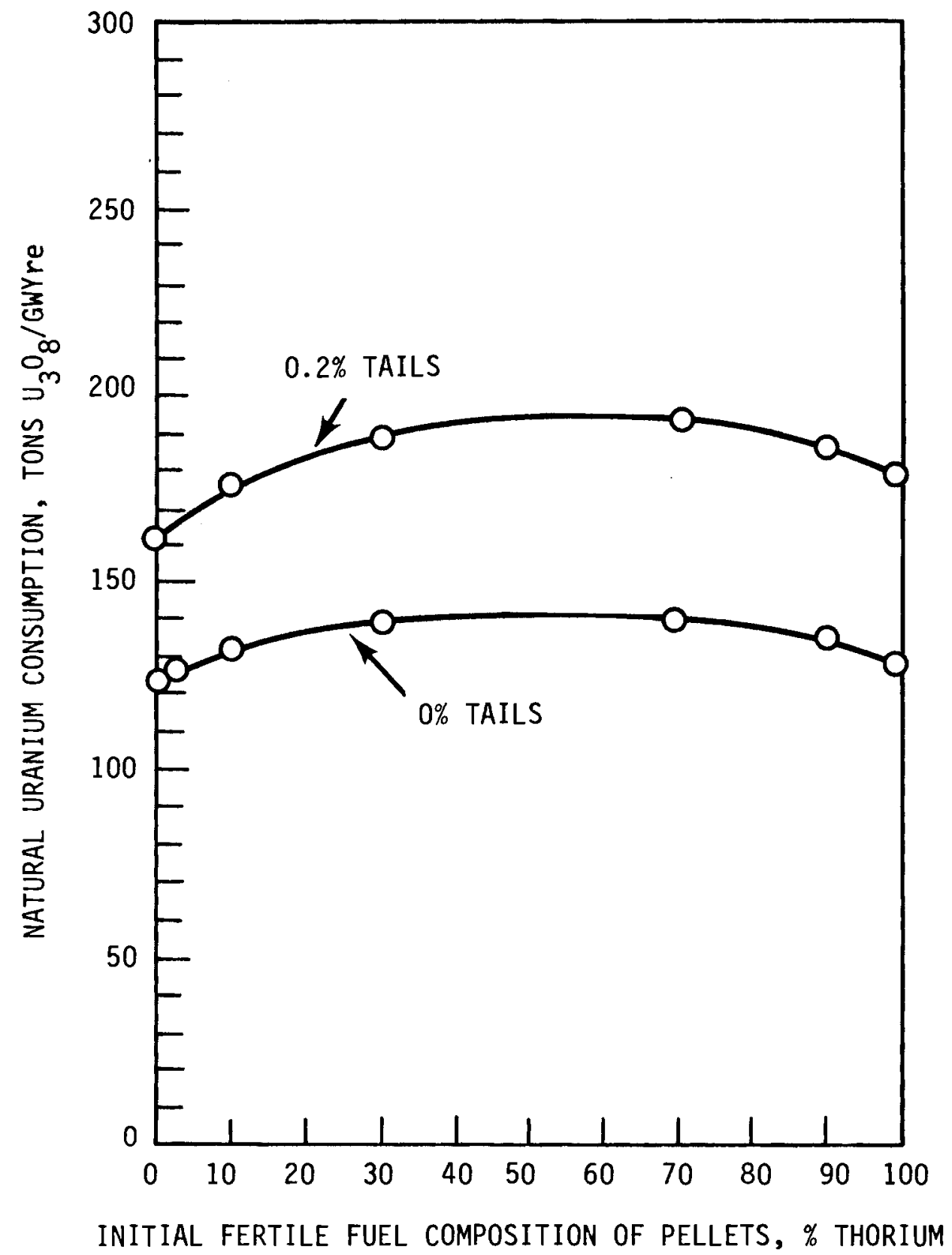

FIGURE 4B. Calculated Uranium Consumption for 5-Year Reactivity Limited Lifetime, Comparing $0 \%$ and $0.2 \%$ Tails for Fixed Lattices 


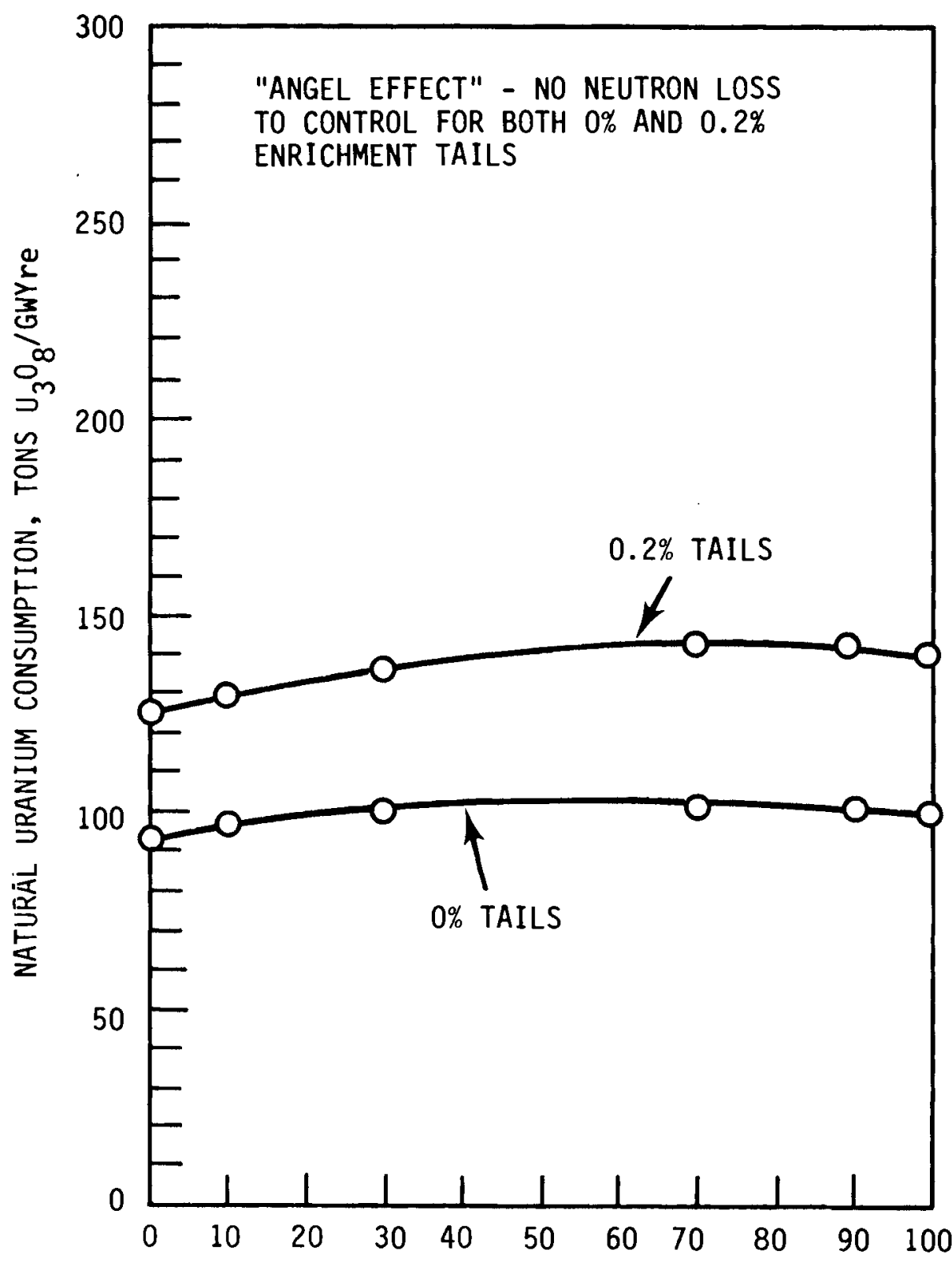

INITIAL FERTILE FUEL COMPOSITION OF PELLETS, \% THORIUM

FIGURE 5. Calculated Uranium Consumption for 5-Year Reactivity Limited Lifetime, Comparing $0 \%$ and $0.2 \%$ Tails with No Neutron Loss for Control 


\section{ANALYSIS OF THE THORIA-URANIA DUPLEX PELLET}

For the reactor physics calculations, a one-dimensional fuel pellet unit cell (infinite reactor lattice) approach was chosen because it is less expensive in computer time and money than a complete multi-dimensional approach. Although reactor spatial effects information is not available using the unit cell approach, the results are not affected because the effects being examined at this time are in the pellet, not in the whole reactor core. In addition, it is simpler with the unit cell approach to separate fuel-loading pattern effects from the effects of the duplex pellet.

A single number, tons $\mathrm{U}_{3} \mathrm{O}_{8} /$ giga-watt year-electric (tons of $\mathrm{U}_{3} \mathrm{O}_{8} / \mathrm{GWY}$ re), was chosen to compare different thoria-urania duplex pellets, as was done for the homogeneous cases described in the previous section. The calculations of tons of $\mathrm{U}_{3} \mathrm{O}_{8}$ /GWYre include: 1) the thermal and operating efficiencies of the reactor, 2) volume fraction of uranium in the pellet, 3) the feed factor to produce the needed enrichment of the urania, and 4) the pellet burnup.

\section{CALCULATION METHODOLOGY}

Iteration for various enrichments is used to determine when different pellets have reached the same level of reactor usefulness in terms of reactivity lifetime and energy generated. The calculation method involves integrating the flux weighted infinite neutron multiplication factor $\left(k_{\infty}\right)$ with time. Fuel goal exposures were ascertained to be the point when their flux-time averaged $k_{\infty}$ equals the minimum operable level, as described previously.

The one-dimensional computer code with burnup, WIMS (Windfrith Improved Multigroup Scheme), a British neutronics computer code, was selected to duplex pellet analysis for several reasons. First, WIMS has been used before to calculate different fuel geometries and is capable of handling the duplex pellet in both thick and onion skin designs. Second, WIMS has a 69 energy-group approach, which is able to accurately predict resonance effects and has been verified against a Monte Carlo code. (a) WIMS also has a large 50 nuclide

(a) J. R. Askew, F. T. Fayer and P. B. Kemshal1. 1966. "General Description of the Lattice Code WIMS." JBNE. 
fission product library for each isotope of interest that should be able to accurately predict burnup effects and to accommodate the differences in poisoning from ${ }^{239} \mathrm{Pu}$ and ${ }^{233} \mathrm{U}$ fission products. Last, WIMS has been verified to yield acceptable overall results for LWR geometries and is being used at Brookhaven National Laboratory to do similar urania-thoria duplex pellet analyses. (a) Use of simpler zero-dimensional cell codes was ruled out for the duplex pellet because the codes would have to smear the two fuel regions into one and fuel smearing would make it impossible to calculate the possible benefits of the duplex pellet.

\section{PELLET DESCRIPTION}

In this study of duplex pellets, $1,3,5,10,30,50,70$, and 90 percent thoria were compared to a standard urania pellet. The pin dimensions are listed in Table 1. The duplex pellet was made by replacing an outer ring of urania with thoria. Urania enrichment for the duplex pellet was initially chosen to reach the relevant standard fuel residence times in terms of MWD/ton of heavy metal in the fuel.

TABLE 1. Fuel Pin Parameters for the Urania-Thoria Duplex Pellet Comparison

$$
\begin{array}{ll}
\text { Pellet diameter, cm } & 0.42 \\
\text { Clad diameter, cm } & 0.49 \\
\text { Pitch diameter, cm } & 1.35
\end{array}
$$

\section{RESULTS FOR THE THORIA-URANIA DUPLEX PELLET}

Use of the thoria-urania duplex pellet for the once-through LWR fuel cycle does not improve uranium use over the standard urania pellet. However, the penalty for using thoria in this fuel cycle is reduced when the fuel exposure period is 3 years rather than 5 years, as shown in Figures 6 and 7 , respectively. The duplex pellet results may be compared with the homogeneous pellet data

(a) A. Mallen, S. Shenoy and H. Ludewig. 1979. CANDU Lattice Physics Code Validation and a Prel iminary Analys is of CANDU Reactor Feedback Coefficients. BNL-NUREG-25572. 


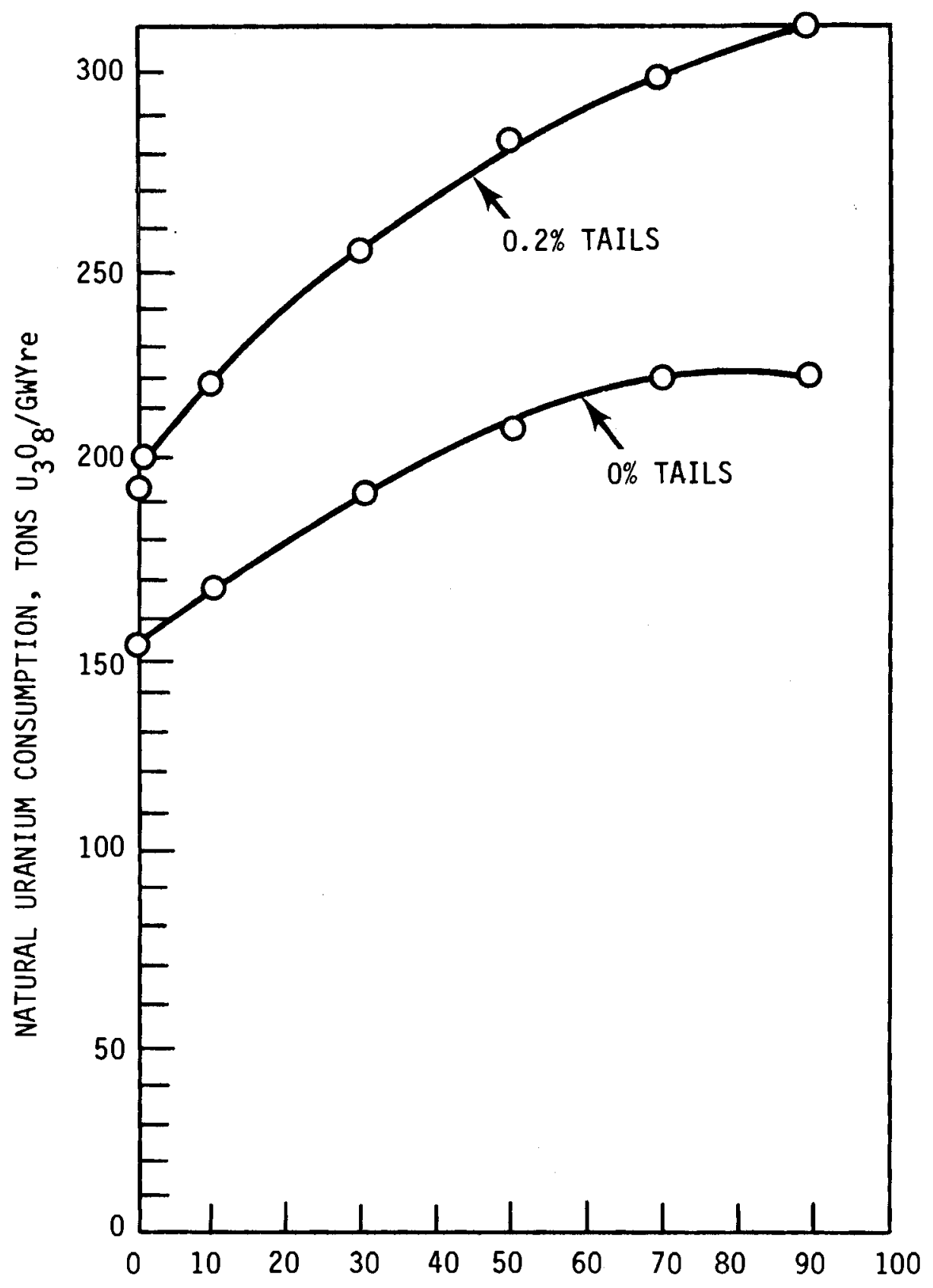

INITIAL FERTILE FUEL COMPOSITION OF PELLETS, \% THORIUM

FIGURE 6. Calculated Uranium Consumption for 3-Year Reactivity Limited Lifetime, Comparing $0 \%$ and $0.2 \%$ Tails for the Duplex Pellet 


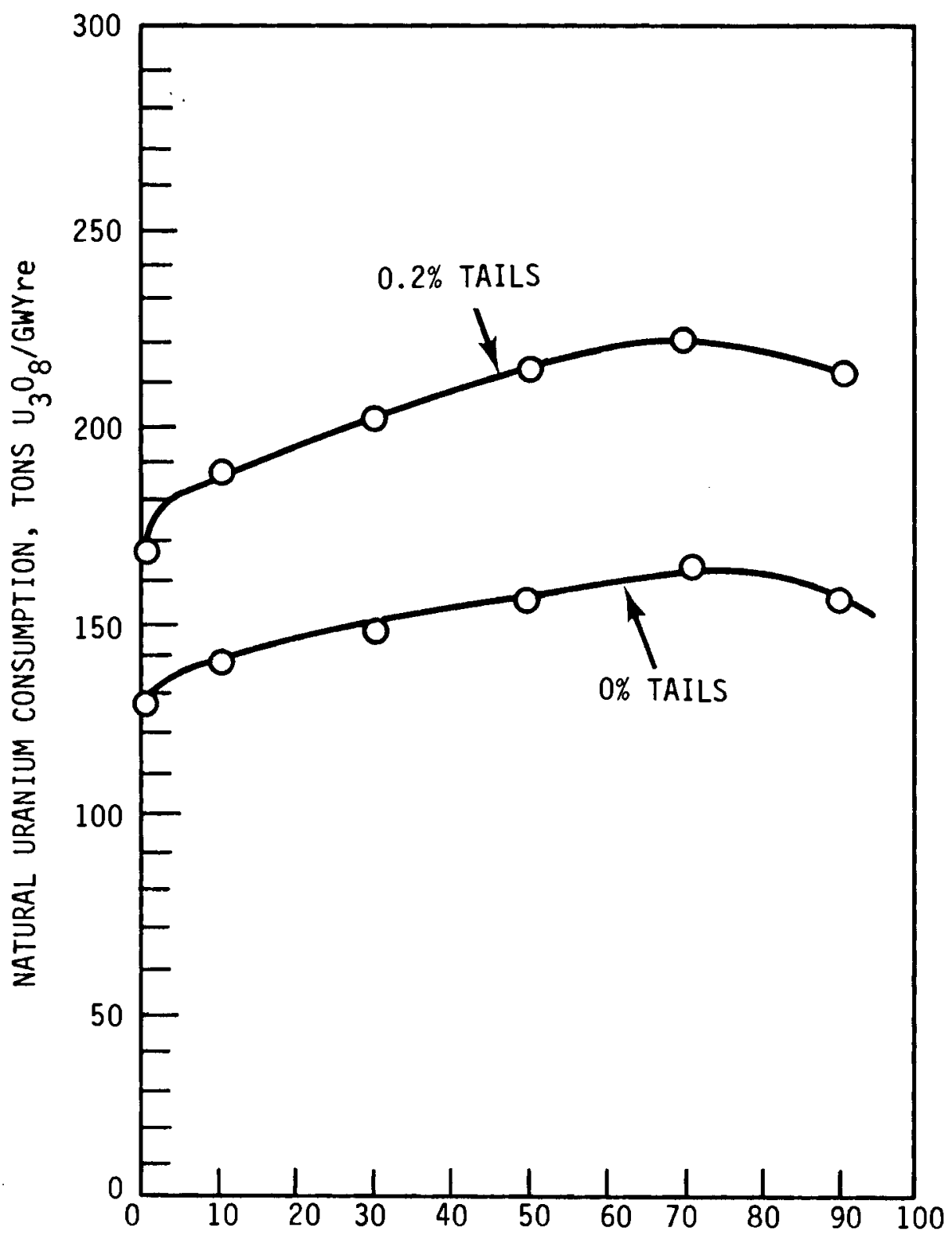

INITIAL FERTILE FUEL COMPOSITION OF PELLETS, \% THORIUM

FIGURE 7. Calculated Uranium Consumption for 5-Year Reactivity Limited Lifetime, Comparing $0 \%$ and $0.2 \%$ Tails for the Duplex Pellet 
presented in Figures 1-5. Some of the features noted in this comparison are a result of the computational codes used. This is discussed more fully in Appendix B. Each code shows about 165 tons of uranium usage per year for urania; the increases of urania utilization with addition of thoria appear greater when the WIMS code is used. While it appears that the homogeneous pellet configuration is more effective in uranium-utilization than the duplex thoria-urania configuration, none of the thoria-urania arrangements performs as well as does 100 percent urania. 
.

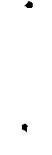

, 
WHY THORIUM $/{ }^{233} U$ DOES NOT CONSERVE URANIUM IN ONCE-THROUGH LWRS

Thorium-additions to uranium do not increase uranium conservation in LWR once-through cycles. This may appear anomalous in view of comparison of some nuclear properties of ${ }^{233} \mathrm{U}$ and ${ }^{239} \mathrm{Pu}$. In particular, on the basis of isolated eta in thermal neutron reactor spectrums, it is conventional wisdom to anticipate that ${ }^{233} \mathrm{U}$ (eta $\simeq 2.3$ ) is a more valuable bred fuel than ${ }^{239} \mathrm{Pu}$ (eta $\simeq 1.95$ ). Accordingly, thorium should appear as a better fertile fuel than ${ }^{238} \mathrm{U}$, and thus substituting some thorium for ${ }^{238} U$ should conserve uranium--but it does not in the cases studied here. This possibility was not wholly unanticipated, however, which is why on page 2 it was pointed out that thorium was to be used as a burnable fertile poison to augment rather than replace ${ }^{238} \mathrm{U}$. The burnable fertile poison was to absorb excess neutrons at the beginning of life but not compete with ${ }^{238} \mathrm{U}$ before the end of life when an ever shorter supply of neutrons is present. The study results show that the initial effective thorium crosssection could not be made large enough to "burn out," even though the ratio of effective thorium resonance integral to ${ }^{238} \mathrm{U}$ resonance integral was indeed made larger than the ratio of the dilute integrals (dilute values $80 / 280=.285$ compared with the ratio of effective integral of $28.4 / 29.9=.95)$ at 30 percent salting of thorium in uranium.

Thus, through many of the burnups analyzed, thorium was competing favorably with ${ }^{238} \mathrm{U}$ for fertile captures; therefore, the relative contribution to nuclear reactivity of ${ }^{233} \mathrm{U}$ and ${ }^{239} \mathrm{Pu}$ becomes of interest. While elementary, it should be kept in mind that the higher eta for ${ }^{233} U$ is derived only when comparing the respective fissile and capture cross-sections of ${ }^{233} \mathrm{U}$ and ${ }^{239} \mathrm{Pu}$ in isolation from other reactor fuel components. In an operating nuclear reactor, all of the other capture cross-sections enter into the formulation of nuclear reactivity. Under these circumstances, ${ }^{233} U$ is at a disadvantage relative to ${ }^{239} \mathrm{Pu}$ in typical LWR spectra because the fission cross-section as well as neutron fission yield for ${ }^{239} \mathrm{Pu}$ is greater than ${ }^{233} \mathrm{U}$. For comparison, then, we should examine the incremental effect upon nuclear reactivity of substituting an atom of ${ }^{233} \mathrm{U}$ for an atom of ${ }^{239} \mathrm{Pu}$. To do this, we have prepared from a burnup computation the respective derivative of reactivity with respect to a change in the concentration of ${ }^{233} \mathrm{U}$ atoms and of ${ }^{239} \mathrm{Pu}$ atoms. The easiest way 
to do this is to form the derivative of $\frac{k}{\rho \varepsilon}$, which is equal to the derivative of $n f$ because $\varepsilon$ and $\rho$ scarcely change when an atom of ${ }^{239} \mathrm{Pu}$ is replaced by an atom of $233_{U}$. (a)

Figure 8 is the plot of the derivative of ${ }^{233} \mathrm{U}$ and ${ }^{239} \mathrm{Pu}$ with respect to $n f$ as a function of the product $n f$. As reactor burnup proceeds, $n f$ is reduced and so is the relative influence of ${ }^{233} \mathrm{U}$ compared with ${ }^{239} \mathrm{Pu}$. Figure 8 was prepared for 30 percent thoria-70 percent urania homogeneous fuel using representative end-of-life fissile specie nuclear densities--namely, ${ }^{235} U-1.5 \times$ $10^{20} / \mathrm{cm}^{3} ;{ }^{239} \mathrm{Pu}-0.75 \times 10^{20} / \mathrm{cm}^{3} ;$ and ${ }^{233} \mathrm{U}-0.75 \times 10^{20} / \mathrm{cm}^{3}$. It can be seen from Figure 8 that ${ }^{233} U$ 's contribution to reactivity is greater than ${ }^{239} \mathrm{Pu}^{\prime} \mathrm{s}$ for values of $\mathrm{nf}$ greater than about 1.7 , but for $\mathrm{nf}$ values less than 1.7 or so, ${ }^{239} \mathrm{Pu}^{\prime} \mathrm{s}$ contribution is greater. LWRs with once-through fuel loads have $n f$ values at the beginning of 1 ife near 1.6 while at the end of 1 ife they are about 1.3. Comparable values for Shippingport loads and HWRs are 2.0 and 1.7 , respectively. Thus, it appears that while ${ }^{233} U$ in HWRs and Shippingport may contribute more to nuclear reactivity than does ${ }^{239} \mathrm{Pu}$, the situation is reversed in current LWRs using the once-through cycle.

\section{THE DILEMMA OF THORIUM FUELS}

of course, it does not translate directly that thoria- ${ }^{233} \mathrm{U}$ loads are economically compelling in Shippingport and HWR designs. Far more than reactivity contribution as investigated here is involved. Lacking a fissile specie in nature akin to ${ }^{235} U$, thoria- ${ }^{233} U$ fuelings begin with economic disadvantages since they require ${ }^{235} U$ or plutonium for startup and makeup. In addition, the substantially higher fast-fission effect in ${ }^{238} U$ as compared with ${ }^{232} \mathrm{Th},{ }^{233} \mathrm{U}$ 's lesser energy yield on fission, and other considerations reduce further the economic competitiveness relative to slightly enriched uranium of the thoria- ${ }^{233} \mathrm{U}$ cycle in LWRs.

Over the past 20 years various investigators have examined the role of the thoria- ${ }^{233} \mathrm{U}$ system and have not been able to show economically compelling prospects that are broad enough to justify starting such a cycle. This study of thorium-salting uranium in once-through fuel cycles was

(a) For this exercise, the equivalent for $n$ from the four factor formula $k=n \varepsilon p f$ was formulated from the $k_{\infty}$ calculation by WIMS. 


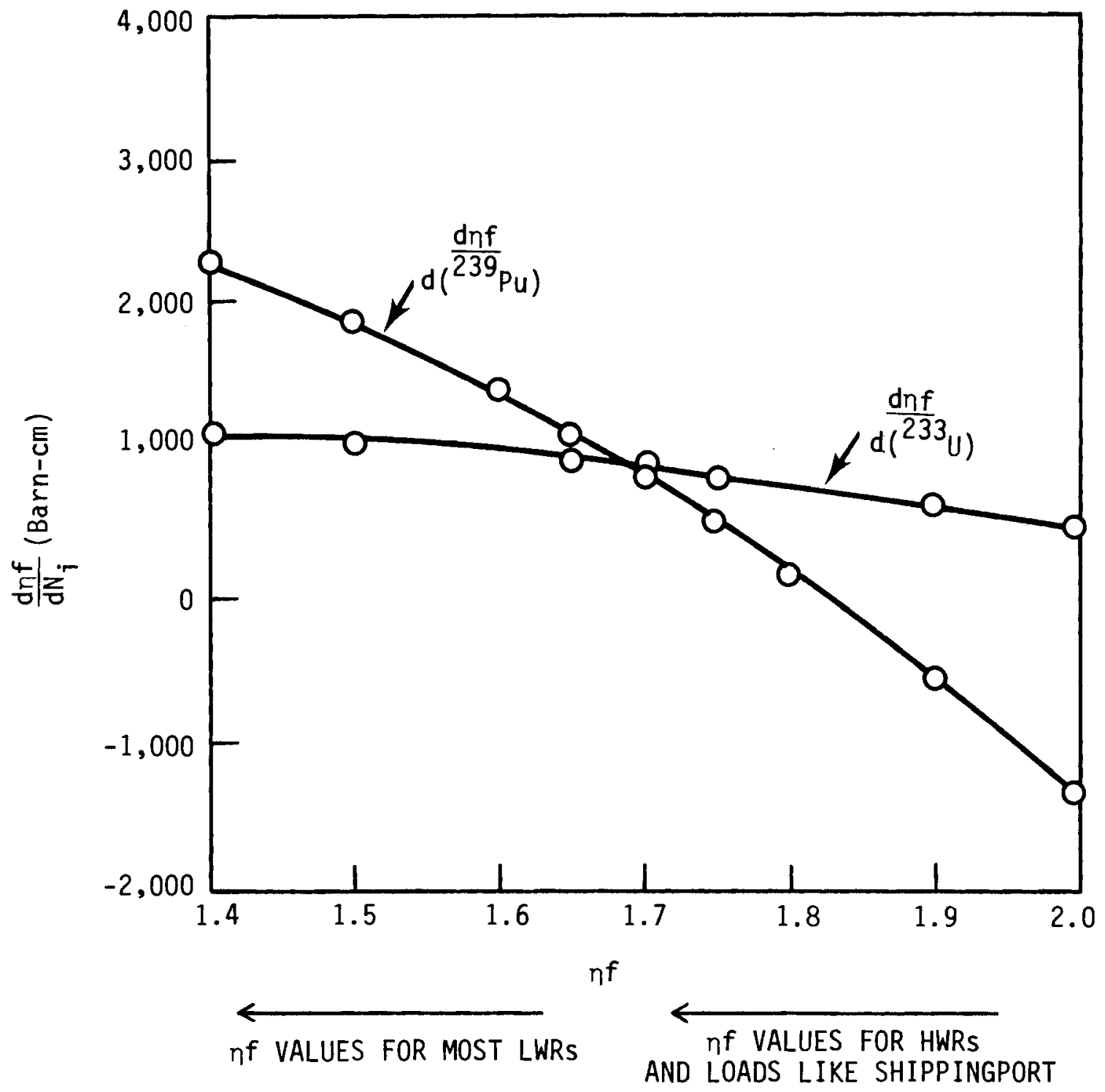

FIGURE 8. Influence on Reactivity of Incremental ${ }^{239} \mathrm{Pu}$ and ${ }^{233} \mathrm{U}$ Additions (For 30\% Thoria/70\% Urania Homogeneous Fuel Case) 
stimulated by the past Presidential desire to defer indefinitely the reprocessing of nuclear fuel. This decision led utilities and government to seek methods to improve the fuel utility of the once-through cycle. In addition to this study, several research review papers and special seminars have added to the literature on thoria- ${ }^{233} U$ usage. (See Appendix A.) Most of the studies involve "free-standing systems" of thoria- ${ }^{233} U$. This study--thoria-urania mixtures--is a combination system. Another combination system that involves considerable fuel processing (previously analyzed) and that may have merit is the use of ${ }^{233} U$ to enrich ${ }^{238} U$ in LWRs and subsequent use of plutonium to produce $233 \mathrm{U}$ in HWR or fast reactors.

In the long run, of course, thorium-based systems will likely be employed, since there is about four times as much thorium in the earth's crust as there is uranium. However, the economic role of thorium systems in LWRs may have to await the development of substantial scarcity of uranium as, technically, thoria- ${ }^{233} U$ systems do not appear substantially better, and often not as good as 100 percent uranium. Such was the case for the thoria-urania mixtures in LWRs investigated here. 
APPENDIX A

SELECTED LITERATURE REFERENCES 
APPENDIX A

\section{SELECTED LITERATURE REFERENCES}

Following is a representative selection of documents published over the past 20 years representing various concepts and analyses of the utilization of thorium and ${ }^{233} \mathrm{U}$. The occasion for the reviews has varied. In the $1960 \mathrm{~s}$, motivation was to see whether or not thorium rather than ${ }^{238} \mathrm{U}$ should be the major fuel of the U.S. nuclear fission power industry. In the 1975-1978 period, thorium and combinations of uranium were considered from the standpoint of possibly enhanced nonproliferation characteristics. And recently, by virtue of inflation, thorium and thermal neutron reactors have again been compared with uranium LWRs and fast breeders. As would be expected, authorships reflect advocacy roles. For example, some authors see improved conservation of uranium with thorium, especially in thermal reactors. Other authors see no reason to change from uranium-based systems in thermal and fast breeder reactors. Virtually all authors agree that before thorium is adapted uranium will have to cost substantially more in relative prices than it does now. Only in a few instances in the following references is thorium directly considered for oncethrough cycles. However, reactor physics and other considerations raised are relevant to once-through cycles and were drawn upon for this study. In addition, contacts were made with other investigators who will be publishing soon regarding thorium-uranium mixtures . 


\section{SELECTED LITERATURE REFERENCES}

1968. The Use of Thorium in Nuclear Power Reactors. WASH-1097. Division of Reactor Development and Technology, Brookhaven National Laboratory.

1976. Matzie, R. A. and J.R. Rec. Assessment of Thorium Fuel Cycles in Pressurized Water Reactors. International Conference on World Nuclear Power.

1977. Deonigi, D. E., et al. Some Alternatives to the Mixed Oxide Fuel Cycle. Pacific Northwest Laboratory, BNWL-2197, Rich1and, Washington.

1977. Kasten, P. R., et a1., "Assessment of the Thorium Fuel Cycle in Power Reactors." ORNL/TM 5565.

1977. "Extraction of Energy from Nuclear Fuels Without Reprocessing to Separate Plutonium." In Proceedings of a Special Session Sponsored by the ANS Nuclear Fuel Cycle Division, 1977 Winter Meeting, pp. 426434, San Francisco, California.

1978. Eschbach, E. A. "Advanced Reactor Fuel Cycles." Pacific Northwest Laboratory. BN-SA-916. Richland, Washington.

1978. Eschbach, E. A. "Some Plutonium Recycle Program Fuel Cycles Having Reduced Proliferation Characteristics." Nuclear Technology. $41(2)$.

1978. Williamson, H. E., et al. Assessment of Utilization of Thorium in BWRs. NEDG 24073. General Electric Co., San Jose, California.

1980. Advanced Fuel Cycle and Reactor Concepts. Report of INFCE Working Group 8. Published by the International Atomic Energy Agency, Vienna.

1980. Colby, M. J., D. B. Townsen, and C. L. Kunz. Safety Analysis of Thorium-Based Fuels in the GE Standard BWR. NEDG 24817. General Electric Co., San Jose, California.

1980. Thorium Utilization in the Nuclear Power Program. R. S. Greeley, ed., the MITRE corporation, McLean, Virginia, MTR-80W54. 


\section{APPENDIX B}

CODE COMPARISON 
APPENDIX B

\section{CODE COMPARISON}

A comparison of the codes ALTHAEA and WIMS was carried out as part of the study. Since WIMS is a far more rigorous approach, it is expected that it is far more authoritarian. ALTHAEA was employed because it was far easier and much less expensive to use.

In the case of the all-urania fuel, the two codes should and do agree; compare the points on Figure 1 (fixed lattice) with those on Figure $6(0.2 \%$ tail) and the corresponding points on Figures 2 and 7 . A direct comparison of these graphs is not possible for thoria-urania mixtures since the fuel geometry is grossly different. The urania is homogeneously mixed in the fuel for the ALTHAEA calculations while it is contained in a central core in the WIMS calculations.

Special computations were therefore done using WIMS to analyze homogeneous thoria-urania fuels in order to compare WIMS and ALTHAEA. In the case of "all-thoria" (highly enriched urania), the agreement was excellent. A comparison of a $30 \%$ thoria/70\% urania $(9 \% 235 \mathrm{U})$ is given in Table B.1. The codes LEOPARD and HAMMER were employed as well in analyzing this case. Note that WIMS agrees with HAMMER AND EGGNIT, while ALTHAEA and LEOPARD appear low in $k_{\infty}$. On the basis of the formulation of these codes, it is believed WIMS, HAMMER, and EGGNIT are likely handling thoria-urania mixtures more correctly. By virtue of the anomalous ratio of effective resonance integrals $\left(\mathrm{Ia}_{238} / \mathrm{Ia}_{232}\right)$ for LEOPARD (.629) compared with the others ( 1.05 to 1.3$)$, it does not appear that LEOPARD handles the urania-thoria mixtures correctly. This may be an anomalous limit to the version of LEOPARD used in the present studies.

Additional computations were made to compare WIMS and HAMMER to duplex fuel geometries. This was done to provide further comparisons on WIMS. Table B.2 lists some key parameters calculated by WIMS and HAMMER for a 30 percent thoria-70 percent urania duplex pellet. Such listings typically show that different codes vary slightly in developing their discrete parameters; however, overall, the agreement is satisfactory. (ALTHAEA, LEOPARD and EGGNIT were not suitable for such applications.) 
As a burnup code, LEOPARD has been carefully calibrated for slightly enriched uranium (100 percent urania, no thoria); thus, Table B.3 compares to the calculated $k_{\infty}$ from WIMS, LEOPARD, and ALTHAEA through a slightly enriched uranium fuel burnup. One notes that WIMS tracks LEOPARD very we11. ALTHAEA tracks but at about .05 less $k_{\infty}$ to essentially zero difference at end of burnup. Thus, for this study, WIMS and ALTHAEA were used, with a compensation in necessary $k$ to bring ALTHAEA into line. Had there been time to find the anomaly of thorium in LEOPARD, it could have been used instead of ALTHAEA.

TABLE B.1. Comparison of Calculated Reactivity Parameters from Several Codes (For Homogeneous Pellet: 30\% Th 9.0714\% 235U in Uranium a .1 GWD/ $\mathrm{Mt}$ )

\begin{tabular}{|c|c|c|c|c|c|}
\hline Parameter & LEOPARD & ALTHAEA & WIMS & HAMMER & EGGNIT \\
\hline$k_{\infty}$ & 1.2537 & 1.2788 & 1.3574 & 1.3963 & 1.3642 \\
\hline$\eta f$ & 1.7873 & 1.77754 & 1.7965 & 1.7680 & 1.7867 \\
\hline$\varepsilon \rho$ & .7014 & .719 & .7556 & .7898 & .7633 \\
\hline$\varepsilon$ & 1.4449 & 1.381 & 1.3562 & 1.3420 & 1.3352 \\
\hline$\rho$ & .4855 & .521 & .5589 & .5885 & .5717 \\
\hline $\begin{array}{l}\phi \text { fast/ } \\
\phi \text { thermal }\end{array}$ & 10.39 & 9.62 & 8.77 & 7.50 & 8.27 \\
\hline $\begin{array}{l}I_{a}-238 / \\
I_{a}-232\end{array}$ & .629 & 1.31 & 1.05 & 1.29 & 1.05 \\
\hline
\end{tabular}

$k_{\infty}$ - neutron multiplication in an infinite lattice.

nf - number of fission neutrons produced by thermal fission of all fissile specie.

$\varepsilon \rho$ - number of neutrons slowed to thermal energy per fission.

$\rho$ - probability of a neutron slowing to the thermal region.

$\varepsilon$ - number of fission neutrons produced by fast fission of all fissionable and fissile specie.

фfast - flux of neutron above $0.685 \mathrm{keV}$.

$\phi$ thermal - flux of neutrons with thermal energies.

$I_{a}-238$ - resonance absorbtion intergal for ${ }^{238} \mathrm{U}$.

$\mathrm{I}_{\mathrm{a}}-238$ - resonance absorbtion intergal for ${ }^{232} \mathrm{Th}$. 
TABLE B.2. Comparison of Calculated Reactivity Parameters from WIMS and HAMMER (For Duplex Pellet: $30 \%$ Th on the Outside o . 1 GWD/Mt, $7.4595 \%$ 235u)

\begin{tabular}{|c|c|c|}
\hline Parameter & WIMS & HAMMER \\
\hline$k_{\infty}$ & 1.31367 & 1.3567 \\
\hline nf & 1.73448 & 1.69199 \\
\hline$\varepsilon \rho$ & .75999 & .8026 \\
\hline$\varepsilon$ & 1.31036 & 1.29475 \\
\hline$\rho$ & .57999 & .61989 \\
\hline$\phi$ fast/ $\phi$ therma 1 & 7.24 & 6.19 \\
\hline$I_{a}-238$ & 29.52 & 19.94 \\
\hline$I_{a}-232$ & 28.61 & 17.15 \\
\hline$I_{a}-238 / I_{a}-232$ & .99 & 1.16 \\
\hline
\end{tabular}

$k_{\infty}$ - neutron multiplication in an infinite lattice.

nf - number of fission neutrons produced by thermal fission of all fissile specie.

$\varepsilon \rho$ - number of neutrons slowed to thermal energy per fission.

$\rho$ - probability of a neutron slowing to the thermal region.

$\varepsilon$ - number of fission neutrons produced by fast fission of all fissionable and fissile specie.

фfast - flux of neutron above $0.685 \mathrm{keV}$.

$\phi$ thermal - flux of neutrons with thermal energies.

$I_{a}-238$ - resonance absorbtion intergal for ${ }^{238} \mathrm{U}$. $\mathrm{I}_{\mathrm{a}}-232$ - resonance absorbtion intergal for ${ }^{232} \mathrm{Th}$. 
TABLE B.3. Comparison of Calculated $k_{\infty}$ with Burnup for $4.5 \%{ }^{235} U$ A11-Uranium Homogeneous Pellet

\begin{tabular}{|c|c|c|c|}
\hline GWD/MT & ALTHAEA & LEOPARD & WIMS \\
\hline $\begin{array}{l}0 \\
.1 \\
.5 \\
1\end{array}$ & 1.29558 & $\begin{array}{l}1.390 \\
1.3514 \\
1.3382 \\
1.3310\end{array}$ & $\begin{array}{l}1.40094 \\
1.35700 \\
1.34800 \\
1.34160\end{array}$ \\
\hline $\begin{array}{l}2 \\
3 \\
5.455 \\
6\end{array}$ & 1.22931 & $\begin{array}{l}1.3209 \\
1.3107 \\
1.2834 \\
1.2791\end{array}$ & $\begin{array}{l}1.33108 \\
1.32035 \\
1.29161 \\
1.28709\end{array}$ \\
\hline $\begin{array}{l}9 \\
10.909 \\
12 \\
15\end{array}$ & 1.17205 & $\begin{array}{l}1.2485 \\
1.2297 \\
1.2205 \\
1.1941\end{array}$ & $\begin{array}{l}1.25499 \\
1.23492 \\
1.22510 \\
1.19731\end{array}$ \\
\hline $\begin{array}{l}16.364 \\
20 \\
21.819 \\
25\end{array}$ & $\begin{array}{l}1.12654 \\
1.08884\end{array}$ & $\begin{array}{l}1.1818 \\
1.1539 \\
1.1394 \\
1.1170\end{array}$ & $\begin{array}{l}1.18449 \\
1.15544 \\
1.14021 \\
1.11681\end{array}$ \\
\hline $\begin{array}{l}27.273 \\
30 \\
32.728 \\
35\end{array}$ & $\begin{array}{l}1.05599 \\
1.02619\end{array}$ & $\begin{array}{l}1.1007 \\
1.0832 \\
1.0633 \\
1.0487\end{array}$ & $\begin{array}{l}1.09936 \\
1.08056 \\
1.06160 \\
1.04615\end{array}$ \\
\hline $\begin{array}{l}38.183 \\
40 \\
43.637 \\
45\end{array}$ & .99836 & $\begin{array}{r}1.0261 \\
1.0145 \\
.9910 \\
.9828\end{array}$ & $\begin{array}{r}1.02464 \\
1.01333 \\
.99010 \\
.98202\end{array}$ \\
\hline $\begin{array}{l}49.092 \\
50 \\
54.547 \\
55\end{array}$ & $\begin{array}{c}.99665 \\
.9225\end{array}$ & $\begin{array}{l}.9578 \\
.9526 \\
.9265 \\
.9241\end{array}$ & $\begin{array}{l}.95736 \\
.95225 \\
.92655 \\
.92415\end{array}$ \\
\hline $\begin{array}{l}60 \\
60.001 \\
65 \\
70\end{array}$ & .8989 & $\begin{array}{l}.8976 \\
.8976 \\
.8733 \\
.8514\end{array}$ & $\begin{array}{l}.89785 \\
.89784 \\
.87351 \\
.85124\end{array}$ \\
\hline
\end{tabular}




\section{DISTRIBUTION}

No. of

Copies

\section{OFFSITE}

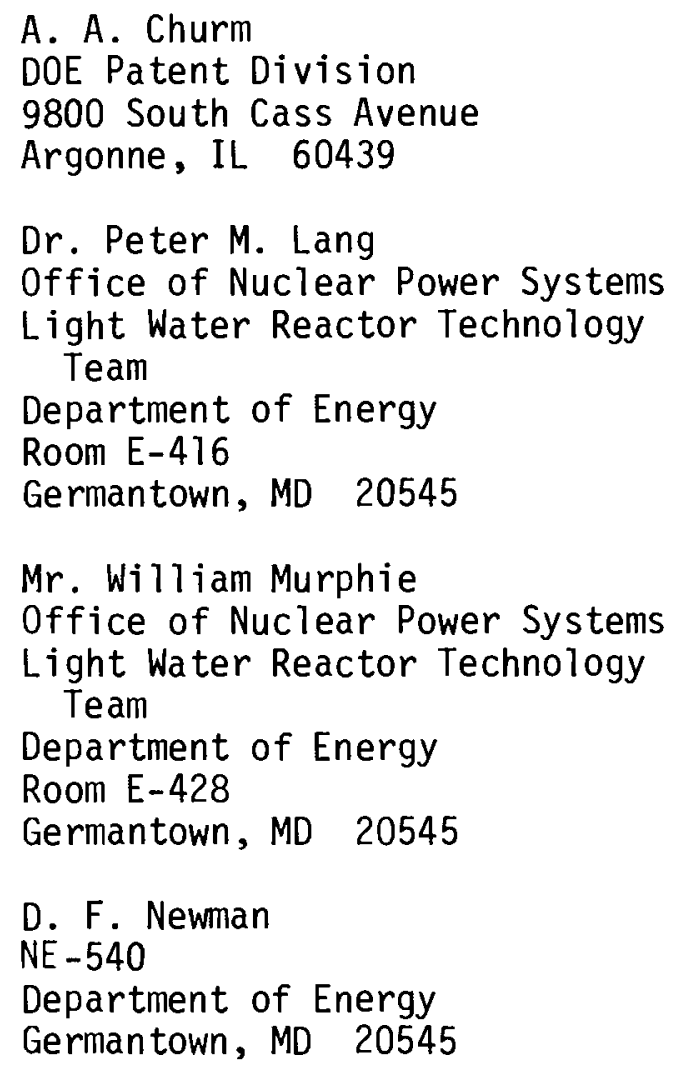

205 DOE Technical Information Center

\section{ONSITE}

DOE Richland Operations Office
H. E. Ransom
P. A. Craig

UNC Nuclear Industries

T. J. Trapp
No. of

Copies

16 Pacific Northwest Laboratory

D. A. Dingee

E. A. Eschbach

R. M. Fleischman

E. T. Merrill

A. W. Prichard

M. L. White

M. S. Freshley

C. L. Mohr

T. D. Chikalla

Publishing Coordination ha (2) Technical Information (5) 
. 